\title{
Equitable academic preparation: A structured onboarding program for incoming graduate nursing students
}

\author{
Edmund J.Y. Pajarillo, Kimberly H. Korn \\ Department of Graduate Studies in Nursing, College of Nursing and Public Health, Adelphi University, Garden City, NY, United \\ States
}

Received: February 2, 2021

Accepted: February 28, 2021

Online Published: March 11, 2021

DOI: $10.5430 /$ jnep.v11n7p1

URL: https://doi.org/10.5430/jnep.v11n7p1

\begin{abstract}
Background and objective: Nurses who return to school to obtain higher education come with varying levels of professional, educational and technological competencies. Some are new graduates, others have not been in school for a decade, and several find educational technology difficult to navigate. Returning to school can be challenging because graduate programs require complex skills in order for students to succeed. Onboarding, the process of organizational socialization, also known as the orientation process, is a relevant element in the retention and progression of students in graduate education. Onboarding differs from school to school, ranging from half a day to a weeklong on-campus orientation. This research is about a structured onboarding program built into a graduate nursing course and specifically addresses the needs of students in order to succeed in their studies. This research presents insights into the Graduate Student Onboarding - Professional Development Program (GSO-PDP), a structured onboarding designed to assist graduate nursing students with their adjustment back to school, enhance their learning, and achieve their graduate degree successfully. It is built into the Nursing Informatics class and is a month-long process. The research offers some understanding of the usefulness of the GSO-PDP to incoming graduate nursing students.

Methods: The study uses the qualitative paradigm, in particular, a case study design. This is an examination of the four modules of the GSO-PDP: Elements of Research, Scholarly Writing and Nursing Documentation, Academic Support Services, and Student Life. Student volunteers participated in focus group interviews to evaluate the program.

Results: The following were recurring themes identified from focus group interviews: "APA Refresher Overload," "Bridging the Gap," "Relearning English Grammar," "Navigating the Learning and University Maze," and "Not Really Computer Savvy." It is evident that most of the elements of the GSO-PDP are beneficial to students in enhancing their adjustment and return to school for further education. The onboarding program also facilitates and enhances student learning. Focus group participants offered some helpful recommendations to improve the program.

Conclusions \& Implications: This is an innovative and structured onboarding approach to help students with diverse backgrounds to succeed in the Master's program. Participants generally described the program favorably, but did make suggestions for improvement.
\end{abstract}

Key Words: Onboarding, Graduate nursing students, Orientation, Higher education orientation

${ }^{*}$ Correspondence: Edmund J.Y. Pajarillo; Email: pajarillo@ adelphi.edu; Address: Department of Graduate Studies in Nursing, College of Nursing and Public Health, Adelphi University, Garden City, NY, United States. 


\section{INTRODUCTION}

Onboarding, commonly known as orientation programs, in higher nursing education is a critical activity to assist nursing students who are returning to school for further education. Research show that onboarding lowers students' stress and anxiety levels about returning to school, ${ }^{[1,2]}$ facilitates program retention, ${ }^{[3]}$ and enhances learning and education. ${ }^{[4,5]}$ Yet, there is no structured onboarding for incoming graduate nursing students built into their program of study that extends beyond the usual few days. Nursing continues to be a dependable profession despite the recent COVID-19 pandemic. Many students choose nursing as their professional degree when it is time to choose a program track. With the recommendations of the Institute of Medicine - Robert Wood Johnson report, ${ }^{[6]}$ "Advancing the Future of Nursing", more students strive to become nurses. Additionally, those who are already nurses are choosing to enroll in higher education. Kiersz and Gillett ${ }^{[7]}$ rank nursing \#1 and nurse practitioner \#14 in a list of 21 most promising jobs of the future. The prediction is that the demand for nurses with graduate degrees will be greater, in order to meet the needs of the increasing number of those enrolled in pre-licensed nursing schools. There is a need for nurses with higher education in both master and doctoral levels to serve as educators of potential and future nurses. In order to assist nurses obtaining higher education, a robust onboarding program needs to be in place to provide academic preparation about specific and targeted topics that will offer them the confidence and foundation to navigate the educational system successfully. This current research describes the results of a structured onboarding for new Master's students.

\subsection{Significance of the study}

Students of higher nursing education begin their program after obtaining varying levels and degrees of professional, technological, and educational experiences. Because of the demand for higher education in nursing, cohorts of nurses enrolling in graduate studies come with variable skills in scholarly writing, critical-thinking, research, use of technology, synthesis of evidence, and information-seeking.

Facing a new cohort of graduate students in their first semester of graduate studies with wide variabilities in knowledge, skills, and experiences is a challenge to educators. A sense of awareness, strong appreciation, and an enormous degree of pedagogical sophistication is required to address the divergent needs of nursing students in graduate programs. Students can likewise be frustrated as they sit through topics that are already familiar to them, while other members of the class struggle to learn subject matters that are new. Students become frustrated and dissatisfied with each other and with the learning experience. It is crucial that the initial courses in the graduate program address students' varying levels of academic preparedness to help them remain and succeed in their particular programs of study. This approach will also help in building a strong community of learners who will support each other throughout their pursuit of higher education.

A structured and targeted onboarding program, patterned after similar non-nursing disciplines ${ }^{[3,5,8]}$ proved to be effective in leveling the playing field for incoming graduate nursing students. The aim is to diminish the disparities in students' professional, personal and technological knowledge, skills, and experiences.

\subsection{Review of literature}

A search of electronic databases for literature related to structured onboarding programs for incoming graduate nursing students yielded nothing. However, some research provide strong evidence of the significance of structured onboarding for other non-nursing graduate programs. Some research focused on structured onboarding for undergraduate nursing students to assist them with their adjustment from high school to college life..$^{[9,10]}$ Most nursing schools offer orientation programs running from a few hours of the day to a weeklong immersion, but nothing that is built-in to the degree program. The purpose of these orientation programs is typically to provide incoming students some familiarization with what the institution and the programs offered. There is nothing in the literature regarding structured onboarding integrated into program courses. Nor is there evidence of an orientation program that extends over a longer period of time, or one that offers assessment and remediation to address the diversity in gaps in students' personal, professional, and technological knowledge, skills, and experiences.

Onboarding in the work setting, also known as “... organizational socialization, is a process through which new employees move from being organizational outsiders to becoming organizational insiders. Onboarding refers to the process that helps new employees learn the knowledge, skills, and behaviors they need to succeed in their new organization". ${ }^{9]}$ Workplace settings traditionally use onboarding; this has evolved to include student onboarding programs in universities and colleges. Medical school programs use the onboarding process with their students resulting in higher retention rates, improved focus and motivation, and selfreported usefulness. ${ }^{[5]}$

Orientation programs are important in establishing expectations, knowledge, and behaviors to assist students to succeed in their particular academic programs. Topics covered in graduate level onboarding programs are professionalism, 
self-care, communication skills, ethics and consent, different learning styles, and course overview. Of the studies reviewed, onboarding entails face-to-face presentations, discussions, distance synchronous learning, or online asynchronous educational modules. The onboarding process also ranged in amount of time - from a day, over the course of a few days, or up to a week. Onboarding, when referred to in nursing literature, refers to the professional orientation of new registered nurses in workplace settings and not in higher education. ${ }^{[11]}$

Zeeman, Wingo, \& Cox $^{[8]}$ evaluated a learner-centered orientation program meant to assist the transition of students to a Doctor of Pharmacy (PharmD) program. Learner-centered orientation is a customized orientation experience, with the goal of preparing first-year students for a proactive curriculum that promotes meaningful, self-directed learning. Their onboarding involved two phases. The first phase was conducted online three months before the start of classes. This covered areas in professionalism, Occupational Safety and Health Administration (OSHA) and Health Insurance Portability and Accountability Act (HIPAA) regulations, curriculum descriptions, introduction to student organizations, peer mentoring, and videos of introductory courses prepared by the professors. The second phase was a one-day orientation held in person where students had the opportunity to engage in discussions, ask questions and advice in round table sessions that promote learner-centered behaviors and self-awareness. After the orientation, students assessed the quality and content of the orientation, their confidence, and their preparedness for the PharmD program. The study extended over three years with three cohorts of first-year students. The result showed an upsurge in students' confidence and in their ability to transition easily in the program. ${ }^{[8]}$

In another study, ${ }^{[5]}$ students entering a medical program in Pakistan had a weeklong orientation that covered topics about professionalism, communication skills, different learning styles, PowerPoint presentations, ethics and consent, medical errors, cultural diversity, student-based learning, empathy, and sympathy. The onboarding was face-to-face and was weeklong. The researchers used both quantitative and qualitative techniques on 65 student-respondents who completed the program. About half of the students (44.6\%) strongly agreed that the objectives of the program were clearly stated and $46.2 \%$ said that the educational environment was safe and conducive to learning. Analysis of the qualitative data revealed that students considered the orientation significant and impactful, and it provided "stimulation and encouragement." Overall, the researchers concluded the orientation to be useful.

Published by Sciedu Press
Arhin \& Wang'eri ${ }^{[3]}$ examined the perceptions and satisfaction of Education and Business students with their orientation program in relation to their retention in a distance-learning program at the College of Distance Education (CoDE) of the University of Cape Coast in Ghana. Researchers used a survey tool for students to self-report their level of perception and satisfaction of their orientation using a 5-point scale. The research outcome showed that students had a positive perception of the orientation program provided at the CoDE. In terms of their satisfaction level, majority of the respondents $(60.6 \%)$ were satisfied and $14.4 \%$ were very satisfied. Additionally, results showed that the probability that students with positive perceptions would remain in the program is 0.85 , while the likelihood that students with negative perceptions would stay in the program is 0.72 . Arhin \& Wang'eri ${ }^{[3]}$ concluded that students perceived the orientation favorably and were satisfied with it. They also found a significant relationship between student perception of the orientation and remaining in the program.

Australian medical students who encounter various stressors and potential burnout in their profession had an immersive orientation called Beginning Education at Central Coast Hospitals (BEACCHES). This intensive orientation facilitated students' transition into their profession, developed social connectedness, and supported student well-being. ${ }^{[2]}$ The two-day program focused on self-care, team building, and encouraged multidirectional interaction among peers, staff, and community. A panel discussion on clinical burnout included examples of scenarios, simulations, cultural narratives, and problem solving. The evaluation was quantitative, comparing participants' pre- and post-program knowledge and personal confidence level scores. Twenty-four students completed the pre-program survey, while 16 completed the post-program survey. The post-program self-rated knowledge scores were significantly higher than the pre-program scores. The authors of the study posited that BEACCHES was a success and recommended to include an assessment of students' wellbeing in future studies.

It is evident from the literature that formal and targeted onboarding programs are effective, enhance learning and retention in the program, and lead to successful completion of educational degrees. Offering similar orientations to incoming graduate nursing students on structured topics, over a longer period of time, and integrated into one of the first courses in the program plan will likely produce beneficial outcomes that are similar to research conducted in non-nursing higher education programs. Research studies reviewed for this current research indicate that onboarding programs yield significant and positive results. Orientation programs offer 
students a general overview of higher education, its complexities and associated workload, and heighten their confidence to succeed and remain in the program. It can also enhance their learning, facilitate adjustment, and narrow the chasm among those who are lacking technological, professional, and personal experiences. ${ }^{[2,3,5,8,12]}$

\subsection{Statement of the problem}

The goal of this current research is to ascertain if a structured onboarding program provided to incoming graduate nursing students offered equitable academic preparedness in higher education. Did this orientation program afford new Master's students with the level of preparedness necessary to stay and complete their respective educational degrees? Additionally, the research will offer insights into the strengths and weaknesses of this tailored onboarding program for structural, content, and process improvements.

\subsection{Program description}

The Graduate Studies Onboarding Professional Development Program (GSO-PDP) is an extensive orientation to decrease personal, professional, and technological disparities among incoming graduate nursing students. This program offers students the necessary familiarization and essential elements to assist them in adjusting to the standard, pace, and complexities associated with higher education. This onboarding is integrated into Nursing Informatics for Advanced Nursing Practice (NUR704), one of two required courses that incoming graduate nursing students take during their first semester. NUR704 is a blended online class $(50 \%$ is face-to-face $(\mathrm{F} 2 \mathrm{~F})$ and $50 \%$ is fully online). Moodle is the learning management platform used for online courses, including NUR704. The NUR704 Informatics course includes the elements of the GSO-PDP under one of its course objectives of "adopting beginning skills in information-seeking, graduate-level writing using evidence-based literature....and accessing [school] and university resources..."

During the first month of the first semester, all sessions of NUR704 are F2F as students complete the GSO-PDP. Students take a post-test upon completion of the onboarding. They must pass the GSO-PDP exam with a score of at least $80 \%$. Students who fail review the GSO-PDP modules again, focusing on the module they failed. They retake the test after two weeks. The GSO-PDP carries points that is part of the students' final grade in NUR704.

There are four components to this onboarding program. First is the use of electronic databases that students use to search for literature about a research topic. This includes thinking of appropriate keywords to find relevant literature, paring search outputs down to the most appropriate literature, developing the outline and describing each major heading, and writing annotated bibliographies. The second element is a review of scholarly writing, which covers the use of APA formatting and Strunk and White's ${ }^{[13]}$ rules of usage, composition, and approach to style. The third part is familiarization of and access to academic support services offered by the University, such as the Writing and Learning Center, Health Services and Counselling, Simulation Laboratory, etc. The fourth component is orientation to graduate student life. This is an overview of the Graduate Student Association, specialty professional association membership, specialty certification, clinical placements, attendance in Graduate Forum, Academic Integrity, etc.

The GSO-PDP also incorporates the "personal approach" that University faculty and staff use to address academic excellence and success, and to improve students' learning experiences.

\section{Methods}

\subsection{Setting}

Adelphi University in Garden City, NY, is the setting for this GSO-PDP, specifically for incoming students of the Department of Graduate Studies in Nursing (DGSN) of the College of Nursing and Public Health (CNPH). The program was piloted in the Spring 2019 cohort of graduate students. This GSO-PDP is the project of the primary author as a Fellow of the Viret Faculty Development Program of Adelphi University.

\subsection{Design}

Being a new initiative, the program was refined a few times before the pilot implementation. The research is qualitative in nature, specifically a case study of five (5) studentparticipants interviewed for this research. The Institutional Review Board (IRB) approved the research protocol prior to conducting the research,

Pilot studies are essential to any innovative programs such as the GSO-PDP. A pilot study is requisite to avoid any disruptions in program delivery and implementation. The case study participants recruited for this pilot willingly volunteered and were promised anonymity in order for them to remain candid, honest and truthful with their comments and recommendations. Participants used fictitious names during the data gathering, discussion, and dissemination of the pilot study results. Since this was a pilot study, implementation was likely to be less disruptive with the participation of the smallest cohort. The Spring 2019 cohort began with 16 students but after five semester terms, the cohort dropped to 
14 students. Out of 14 , only 5 willingly participated in the research.

\subsection{Data gathering}

After obtaining approval from the Institutional Review Board (IRB) of the University, a Graduate Research Assistant (GRA) conducted focus group interviews of the case study participants. In order to record the focus interviews, the GRA explained the research purpose and the need for audio recording to provide participants the choice between participating and opting out. Interviewees used their assigned fictitious names during the focus groups. The GRA had an interview guide that was unstructured, and provided her some leeway to adjust the questions in order to validate responses, and requests for elaborations from other participants. Interview questions covered a wide range of topics. Some interview questions were:

(1) What elements did you like best and least in the GSOPDP?

(2) What topics were stimulating or irrelevant?

(3) Did you like the GSO-PDP? Why? Why not?

(4) Was the GSO-PDP beneficial to you or not?

(5) Did the program help you adjust to being back to school?

(6) Should the GSO-PDP be integrated into the program of study or not?

(7) Did the GSO-PDP make it easier for you to progress in your studies or not? Why? Why not?

(8) What elements of the program will you recommend modifications?

The GRA allowed the participants to express anything they wished to say in order to get a better sense of the effectiveness of the GSO-PDP, its strengths and weakness, and the overall usefulness and relevance of a structured onboarding program for graduate nursing students.

\subsection{Methods of analysis}

With qualitative research, "textual data management is reductionist, while textual data analysis is constructivist." ${ }^{[14]}$ The authors used content analysis to examine transcribed audio recordings of focus group interviews. This case study delved into the depth and breadth of the structure, elements, and processes of the onboarding project. During the conceptualization and planning of the research, the authors decided content analysis of interview transcripts was the most suitable data analysis method for assessing the effectiveness of the GSO-PDP. Since the GSO-PDP is a new initiative, there was no precedent to use as a standard for measuring its effectiveness. Content analysis was beneficial in determining any recurring themes that provided descriptive insights into the participants' evaluation of the program. The recurring themes offered appraisals of particular elements of the GSOPDP as analyzed individually and in conjunction with the rest of the themes arising from the constructivist analysis of textual data. Adding a quantitative survey of a small cohort of students would not have offered the same rich data obtained from the focus group interviews. Moreover, the return rate for a survey of a small cohort of 14 students would have been very low.

\section{RESULTS OF THE CASE STUDY}

\subsection{Description of participants}

Five (5) participants of the GSO-PDP enrolled in the graduate nursing program volunteered to join the focus group interviews in the data gathering phase. Four (4) participants were female and one (1) was male. All had completed the GSO-PDP during their Nursing Informatics course during their first semester and the inaugural implementation of the GSO-PDP. All of the participants are still in their respective graduate nursing programs. Participants ranged from recent baccalaureate graduates to students who had been out of school for about ten years.

One participant graduated with a bachelor's degree in 2010 and is currently working as a medical-surgical nurse in a local hospital while going to school to become an AdultGerontological Primary Care Nurse Practitioner (AGPCNP). She says she is not computer savvy, but tries to learn new things so she can keep up at work with changing software programs.

Another has been a nurse for almost 7 years. She initially had an associate's and then received her baccalaureate degree in 2017. Though she considers herself a millennial, she would not say she is computer proficient, but "just okay". She is in the Psychiatric Mental Health NP (PMHNP) program.

A third participant graduated with a bachelor's degree in nursing in 2014 and has been a nurse for five years. She is a millennial, but does not think she is quite good with her computer skills. She also does not like technology and thinks it is not good for our society. She is also in the PMHNP program.

One participant has been working as a nurse for two years and is currently in the PMHNP program. He says that he can use a computer, but is not the best at it and has over ten years of computer experience.

The fifth interviewee graduated with a bachelor's degree in 2003 and has been a nurse for 14-15 years. She uses a computer at work, but she claims she does not use it at home that much. When she returned to school after 15 years, she says that the educational technology was very different from what 
she previously used.

\subsection{Recurring themes \& analysis}

All five (5) participants reported that the GSO-PDP was helpful and useful to them. When asked about their initial thoughts before starting the program, the participants stated they felt they were "the test case", since they were the first cohort to undergo the GSO-PDP. They also felt it might be more work for them on top of their Informatics coursework. However, many saw the value of the program and understood that its goal is to decrease the varying levels of competencies in technological, educational, and professional skills. They also understood that the nursing program requires proficiency on topics included in the GSO-PDP in order to succeed in the program. Content analysis of the interview transcript showed the following themes repeatedly brought up by the participants: "APA Refresher Overload," "Bridging the Gap," "Relearning English Grammar," "Navigating the Learning and University Maze," and "Not Really Computer Savvy." The participants verbalized a pervasive theme of apprehension throughout the start of the semester. However, this eventually diminished once everyone completed the onboarding portion of the course.

\subsubsection{APA refresher overload}

Participants agreed that the program helped them write better using the American Psychological Association (APA) style of writing and formatting. It is a way of "re-teaching or cementing" the rules. Principles of adult learning (andragogy) support immediate application of learning by way of repetition, constant practice, and relatability to current needs and past experiences. ${ }^{[15-18]}$ Adult students are encouraged to relate new learned subject matters to prior experiences, apply learned topics at the first opportunity, and use newly-learned concepts repeatedly. Integrating APA style of writing in the GSO-PDP makes sense in nursing graduate studies because of the volume and frequency of scholarly writing involved in the program. Adult learners are not encouraged to memorize; instead, students improve and retain what they learn by understanding the principle behind newly introduced theories and concepts. The use of APA does not require them to memorize formatting rules, but to understand whether use of formatting style is necessary, and to refer to the APA resource guide in Moodle to find the correct format to use. Adult learners perform best when self-learning and resourcefulness are encouraged, and when they use the reference guide as necessary. In addition, collateral skills required for scholarly writing are finding suitable resources, navigating databases, and creating annotated bibliographies. One participant said, "that the best takeaway lessons in this particular [onboarding] module are finding resources on the Moodle website ... where to search for particular information, and being exposed to a variety of resources." Another student said that "the Student Writing Center, unbeknownst to me, is available and that I could submit my papers for critique and guidance. More importantly, I am unaware that this service is included in the fees I pay the university." On the opposite end of the spectrum, two participants did not think annotated bibliographies were helpful and viewed them as additional steps in the research and writing process.

\subsection{2 "Bridging the gap: The divide in academic prepared- ness"}

Another recurring theme of the interviews pointed to how the program "bridged the gap" between students who have been out of school for some time (over 10 years) and students who graduated recently or only a few years ago (between 2 - 6 years). Differences in competencies make teaching and learning more challenging. Students who feel they do not belong because of their lack of certain skills become less confident and less likely to succeed. It is the responsibility of educators to identify these competency gaps among students and work with them to fill these gaps. ${ }^{[12]}$ The participants agreed that many students found the onboarding program helpful in many ways. One participant stated, "Yeah, it was necessary. We need to decrease the differences among us when it comes to our [beginning] knowledge and skills when we began the program. People came from different levels [in their nursing career]. [With this onboarding] everybody's on the same level." Another student agreed and said, "I think it was necessary for everyone in different ways. If one part was easier for you, maybe another part was not. [Considering it in its entirety], everyone took away something from it [onboarding]." With the publication of the Institute of Medicine - Robert Wood Johnson (IOM-RWJ) report "Advancing the future of nursing: Leading change, advancing health,", ${ }^{6]}$ more people want to become nurses. Among those who are already licensed nurses, going back to school for higher education, either in the baccalaureate, master's or doctoral level, is becoming a natural progression. This brought to light "educational mobility" where nurses go back to school to acquire knowledge and skills through formal or informal ways. The education of these students must incorporate principles of adult learning in order to accommodate variabilities in age, education, and skillset. ${ }^{[19]}$

A suggestion from focus group participants was the addition of a peer mentoring aspect to the program. One interviewee stated that, "If the GSO-PDP is to help students adjust to the nursing program, then having a peer student who is a semester ahead of us can offer advice and wisdom." Another participant said, "So you're assigned a mentor and if it works, it works. I think that is a great idea. Because it gives me mo- 
tivation, knowing that success in the program is attainable. [The peer mentor] provides a good perspective because it comes from somebody who has done it already." The rest of the participants agreed with this statement. There is evidence in the literature that other onboarding programs served as an opportunity for students to be engaged in discussions with those already in the program and ask questions in "round robin sessions" to promote learner-centered behaviors and self-awareness. ${ }^{[8]}$

\subsubsection{Relearning English grammar: 'I've been speaking English since I was a child"}

Some participants recommended modification of one part of the onboarding program that dealt with language and parts of speech. One interviewee said, "That [part of the onboarding] felt 'extraneous' to native English speakers." Other native English speakers agreed and stated, "When English is your first language, you don't really even think: 'What is a noun? What is a pronoun?' It just flows. I am sure you learned that at some point [but you don't know what it's called]. If English is your second language, you might be thinking that way [using the basic grammar rules]." However, one participant who is not a native English speaker said, "That part of the program was a review and a refresher". Some participants were able to see the value of relearning the basic and formal rules of written English when integrated in onboarding. The participants suggested that this element of onboarding be restructured and should not include quizzes. One participant said, "I understand the point of it and the purpose of it, I get it. However, I feel it could have been designed maybe a little bit differently." This approach emphasizes the relevance of a tailored approach to onboarding where topics address the specific needs of students.

\subsubsection{Navigating the learning and university maze}

All the focus interview participants agreed about the usefulness of both the third and fourth modules of the onboarding - "learning the various resources available in the university" and "orientation to graduate student life". One participant deemed that the resources found on Moodle were useful, such as how to access services offered by the Learning and Writing Center, finding the dining hall and hours of operation, Student Counseling Services, religious activities, etc. Another participant agreed that learning how to navigate a new university campus was useful. One other participant also agreed about the usefulness of learning how to use the library website effectively, when searching resources using various electronic databases and search engines. Topics like these might seem mundane, but these are practical and invaluable skills for students who are returning to a rapidly evolving educational environment. For some students, lack of awareness about resources and services that are available and accessible

Published by Sciedu Press to them can lead to dissatisfaction. These serve as their lifeline in adjusting back to school and succeeding in their quest for higher education. When a cohort of students learn how to navigate and access the university resources together, a stronger bond exists, and the likelihood of building a tightlyknit community of learners is more likely. When support, availability and access to resources is robust, the likelihood for success in learning is greater. ${ }^{[20,21]}$

\subsection{5 "Not really computer savvy"}

Some participants admitted that they were not computer and technology savvy. Even millennial participants considered themselves not to be very computer literate. One student did not use technology growing up, as she was much older than the rest of the group. This participant considered age to be a barrier in learning. "I'm not really computer savvy, but I try to learn a lot of things so I can be good at my job. We recently transitioned to a different computer program at work. It is hard for me because I am not that good with computers. I am learning little by little. I do the same in school. I try my best to learn how to use technology" Another millennial also admitted that she was not that great with computers. One millennial participant stated that she was not comfortable with the use of technology, saying, "I'm also a millennial, but I don't think I'm that computer savvy. I do not like technology. I see the value in it, but I think it's not good for our society." From this discussion, it is evident that age is a factor, at least among those who are older. However, even millennials consider themselves not as proficient in computer and technology use. While this is telling, this is not at all surprising. When electronic health records (EHRs), bar code medication administration systems (BCMA), computerized provider order entry systems, (CPOEs) and other types of technologies first swept the clinical work settings, nurses' reactions ranged from plain discomfort to being fearful and petrified.

\section{Discussion of RESUlts}

It is evident from the identified recurring themes of the focus group interviews that most of the elements of the GSO-PDP are beneficial to students in enhancing their adjustment and return to school. The onboarding program also facilitates and enhances their learning. Notably, students considered knowing available academic services and resources and the orientation to graduate student life to be most helpful. It is understandable that students have the most favorable comments about these two aspects of the GSO-PDP because knowledge of services, resources, and the many aspects of navigating graduate education are lifelines to students' academic success. Regardless of their program track, knowing how to access help is a practical element that determines stu- 
dent satisfaction or dissatisfaction with their academic life. Graduate students are busy juggling many responsibilities and the inability to easily "navigate the maze" and readily access educational resources is a major deterrent to success.

Another agreement among participants of the focus group interviews is the important value of the GSO-PDP. This onboarding program serves to "bridge the gap" among incoming graduate students with diverse experiences, knowledge, and skills. Students benefit from each other when they are all at the same level, and each can contribute to the learning and education of the rest of the cohort. This facilitates the development of a community of learners where members derive personal, professional, and academic support from each other, thereby strengthening camaraderie and creating a strong network of learners with similar aims and goals. ${ }^{\text {[21] }}$ Program satisfaction, retention, and success are achievable.

It also seems clear that age has nothing to do with computer proficiency. ${ }^{[22]}$ While millennials easily adopt to technology, older adults have shown to adopt quicker since 2012, especially among Gen Xers and Baby Boomers. The responses of the focus group participants to the question relating to computer proficiency did not seem to relate to their age. It is likely that age is not a factor when looking into students' computer and technology competence. Almost all graduate students work in healthcare systems that continually have new technologies introduced in their work settings. Regardless of age, every one of them has to contend with getting used to the technologies they have at work.

Students also consider the research component of the GSOPDP to be helpful in their studies. The value of this part of the GSO-PDP is exemplified in one participant's statement, "that the best takeaway lessons in this particular [onboarding] module are finding resources on the Moodle website... where to search for particular information, and being exposed to a variety of resources." The research element of the onboarding is large in scope, but all the topics are important for students' retention, learning, and success in the program. Most focus group participants understand its importance despite contradictory responses by two participants who stated that "annotated bibliographies are not helpful and are additional steps in the research and writing process."

There are notable suggestions, such as restructuring the review of the basics of English and the rules of grammar. Taking their suggestion and the targeted nature of the GSO-PDP into consideration, the onboarding will have this change incorporated in the next academic year. Incoming graduate students will take an exam on the topic of written English and rules of grammar. Should they successfully pass the exam, they will skip this module of the GSO-PDP. Should they fail, they will have to take the module and pass the quiz associated with this topic.

Another valid and important suggestion is the integration of peer mentoring. The GSO-PDP will also adopt this recommendation in the next academic year.

\section{CONCLUSIONS \& RECOMMENDATIONS}

The resounding conclusion from the GSO-PDP study is that it is helpful and valuable to the success of graduate students' learning, retention, and success in the Master's program. Participants of the focus group interviews provided significant and relevant feedback regarding the strengths and weaknesses of the program and offered practical recommendations for improvement.

Onboarding provides value in getting students acclimated to their program of study, offers opportunities for networking and building a robust community of learners, and serves as a tool to identify basic competency gaps in order to offer specific and targeted orientation.

It is important to point out the limitations of this study. This is exploratory research of the effectiveness of the GSO-PDP involving a small number of students. Results are not generalizable to the entire cohort or the population at large. There will be adjustments made to the GSO-PDP incorporating participants' suggestions. Once these are implemented, a more extensive and rigorous study will be conducted.

There is hardly any research on graduate nursing student onboarding, particularly those conducted over some time, integrated into a core course, and specific in terms of the foundational topics needed by incoming graduate students in nursing. It is our hope that we have inspired other graduate programs in nursing to consider the structure and framework of this GSO-PDP and offer the same onboarding program or its iteration to heighten student retention, satisfaction, learning and success in graduate programs. Students will then be able to gain more from their overall graduate school experience.

\section{ACKNOWLEDGEMENTS}

The authors wish to thank the five graduate nursing students who participated in focus groups to provide insights into this research and Abigail A. Smith, MSLIS, Senior Assistant Librarian, SUNY Upstate Medical University, Syracuse, NY, for the meticulous editorial work on this manuscript. More importantly, the first author, a Fellow of the Adelphi Uni- 
versity Viret Faculty Development Program, acknowledges the financial support and recognition accorded by the Viret Family of the Stago Pharmaceutical Company, to establish and implement this research project as part of the fellowship program.

\section{CONFLicts OF INTEREST Disclosure}

The authors declare that there is no conflict of interest.

\section{REFERENCES}

[1] Hullinger M, Hogan RL. Student anxiety: Effects of a new graduate student orientation program. Administrative Issues Journal: Education, Practice \& Research. 2014; 4: 27-34. https : //doi . org/10 $.5929 / 2014.4 .2 .3$

[2] Short B, Lambeth L, David M, et al. Immersive orientation programme to improve medical student integration and well-being. The Clinical Teacher. 2019; 16: 323-328. PMid:31317674 https : //doi.org/10.1111/tct.13077

[3] Arhin V, Wang'eri T. Orientation programs and student retention in distance learning: The case of University of Cape Coast. Journal of Educators. 2018; 15: 1. https : //doi .org/10.9743/JE02018. 15.1 .6

[4] Strydom JF, Mentz M. Should orientation for higher education teaching and learning be better? South African Journal of Health Education. 2008; 22: 1088-1096. https://doi.org/10.4314/sajhe. v22i5. 42930

[5] Ramzan M, Khan KW, Bibi S. Orientation programme for first year medical students: A qualitative study. Pakistan Armed Forces Medical Journal. 2018; 68(5): 1332-1338.

[6] Institute of Medicine (US) Committee on the Robert Wood Johnson Foundation Initiative on the Future of Nursing, at the Institute of Medicine. The future of nursing: Leading change, advancing health. Washington (DC): National Academies Press (US): 2011.

[7] Kiersz A, Gillett R. 21 High-paying jobs of the future. The U.S. Bureau of Labor Statistics predicts major job growth in the health care industry. Inc. This Morning. 2017. Available from: https://www.inc.com/business-insider/best-job s-of-the-future-2017.html

[8] Zeeman JM, Wingo BL, Cox WC. Design and evaluation of a two-phase learner-centered new student orientation program. Currents in Pharmacy Teaching and Learning. 2018, 10: 486-492. PMid:29793711 https://doi.org/10.1016/j.cptl.2017.12 .020

[9] Sparacino L, Diggle S. Reducing perceived stress through an orientation program for nursing students entering their first nursing course. Journal of Nursing Education and Practice. 2017; 7(9): 54-60. https://doi.org/10.5430/jnep.v7n9p54
[10] Altman MI, Musselman M, Curry L. Success begins in nursing freshman orientation course. Nurse Educ. 2010; 35: 6-7. PMid:20010256 https : //doi.org/10.1097/NNE.0b013e3181c41f7b

[11] Pertiwi RI, Hariyati TS. Effective orientation programs for new graduate nurses: A systematic review. Enfermeria Clinica. 2019; 29(S2): 612-618. PMid:31303521 https ://doi.org/10.1016/j . enfcli.2019.04.094

[12] Webster M. Impact of orientation programs on nontraditional students' perceived academic success in adult education programs. 2016. Walden Dissertations and Doctoral Studies.

[13] Strunk W, White EB. The elements of style, 4th ed. 1999. London: UK, Pearson.

[14] Polit D, Beck CT. Nursing research. Generating and assessing evidence for nursing practice. 2012. Philadelphia: PA. Wolters Kluwers Health.

[15] Knowles M. The adult learner: A neglected species. 1973. Houston: Gulf Publishing Company.

[16] Knowles M. Andragogy in action. 1984. San Francisco: Jossey-Bass.

[17] Arghode V, Brieger EW, McLean GN. Adult learning theories: Implications for online instruction. European Journal of Training and Development. 2017; 41(7): 593-609. https ://doi.org/10.110 8/EJTD-02-2017-0014

[18] Knowles MS, Holton EF, Swanson RA. The adult learner: The definitive classic in adult education and human resource development. 7th ed. 2011. Oxford, UK: Butterworth-Heinemann.

[19] Leigh K, Whitted K, Hamilton B. Integration of andragogy into preceptorship. Journal of Adult Education. 2015; 44(1): 9-17.

[20] Bauer TN, Erdogan B. Organizational socializations: The effective onboarding of new employees., APA Handbooks in Psychology. 2011. Washington, DC, US: American Psychological Association.

[21] Laverick EK. Building a community of learners in and outside the classroom. Journal of International Student. 2018; 8(2): 1256-1263. https://doi .org/10.32674/jis.v8i2.145

[22] Vogels E. Millennials stand out for their technology use, but older generations also embrace digital life. Pew Research Center. 2019. Available from: https://www.pewresearch.org/fact-tank/ 2019/09/09/us-generations-technology-use/ 